\title{
Cotton and Wool: Textile Economy in the Serakhs Oasis during the Late Sasanian Period, the Case of Spindle Whorls from Gurukly Depe (Turkmenistan)
}

\author{
Dominika Maja Kossowska-Janik ${ }^{1^{*}}$ \\ ${ }^{1}$ Antiquity of Southeastern Europe Research Centre, University of Warsaw, Warsaw, Poland. \\ *dominikakossowska@yahoo.pl
}

Abstract Gurukly Depe is an archaeological site located in the Serakhs oasis in southeast Turkmenistan, excavated since 2010 by the Polish-Turkmen archaeological mission directed by Professor Barbara Kaim from the University of Warsaw. Most investigated structures date to the Late Sasanian Period. At the site 102 spindle whorls were found. Based on their dimensions and weight I propose that most them were likely to have been used to spin cotton. This evidence provides another indication of cotton agriculture in Central Asia before the Muslim conquest.

Received April 17, 2016

OPEN ひACCESS

Accepted October 20, 2016

DOI 10.14237/ebl.7.1.2016.682

Keyword Spindle whorls, Cotton, Turkmenistan, Gurukly Depe, Sasanian Empire

Copyright (c) 2016 by the author(s); licensee Society of Ethnobiology. This is an open-access article distributed under the terms of the Creative Commons Attribution-NonCommercial 4.0 International Public License (https://creativecommons.org/licenses/by-nc/4.0), which permits non-commercial use, distribution, and reproduction in any medium, provided the original author and source are credited.

\section{Introduction}

Spindle whorls are not the most spectacular objects found by archaeologists, which is probably why they are so seldom discussed at length in archaeological publications. However, these finds deserve more attention as the collected data can yield important information about ancient societies. A study of these artifacts can help determine what was being spun at the site, therefore what fiber materials were used in a region. Dimensions and weight of spindle whorls determine thickness of yarn and these parameters differ according to the fiber chosen for spinning. In this paper, I examine spindle whorls found at Gurukly Depe, Turkmenistan, during the Late Sasanian Period (sixth to seventh centuries AD), to try to establish whether wool or cotton was spun there.

\section{Gurukly Depe}

Gurukly Depe is an archaeological site located in the Serakhs oasis in southern Turkmenistan on the border with Iran, approximately $100 \mathrm{~km}$ from the Afghan border (Figure 1). The oasis was inhabited at least from Neolithic times. From the Achaemenid period up to the Muslim conquest, the region was part of several Iranian empires. Gurukly Depe is a rectangular depe (flat-topped mound) covering 2.8 hectares in area and is 13 meters high. Six seasons of excavations (2010-2015) were conducted by the Polish-Turkmen archaeological mission directed by Professor Barbara Kaim from the University of Warsaw. ${ }^{1}$ The site was identified as a ParthianSasanian (third century BC to seventh century AD) qala: a fortified residence, widely considered typical of Central Asian oasis settlements (Kaim 2011:207). Trenches were excavated in different parts of the depe: on the highest, southwestern area (sectors 10I$10 \mathrm{~J}, 11 \mathrm{~F}-11 \mathrm{t}$, and $12 \mathrm{~F}-12 \mathrm{~K}$ ), where the presumed landowner's residence was probably located; the northwestern part (sectors 6I-6J and 7I); the lowest part $(5 \mathrm{M}-5 \mathrm{~N}, 6 \mathrm{~N}$, and $7 \mathrm{~N})$; and on the fortification wall $(2 \mathrm{~N}, 5 \mathrm{R}-5 \mathrm{~S}, 13 \mathrm{I}$, and $14 \mathrm{I})$. The spindle whorls discussed here were found both on the surface and in most excavated trenches dating to the Late Sasanian (sixth to seventh centuries AD). Contexts were dated by ceramic analysis, as typical for Late Sasanian to Early Islamic sites in this region. ${ }^{2}$ Of course, some whorls from the surface and near-surface excavations could be residual and date to later periods. Remains of Islamic occupation from eleventh century $\mathrm{AD}$ (Gurukly Shaheri) are at the base of Gurukly Depe (Różańska-Kardaś 2013), but Gurukly Depe was not occupied at that time. The oldest datable material 


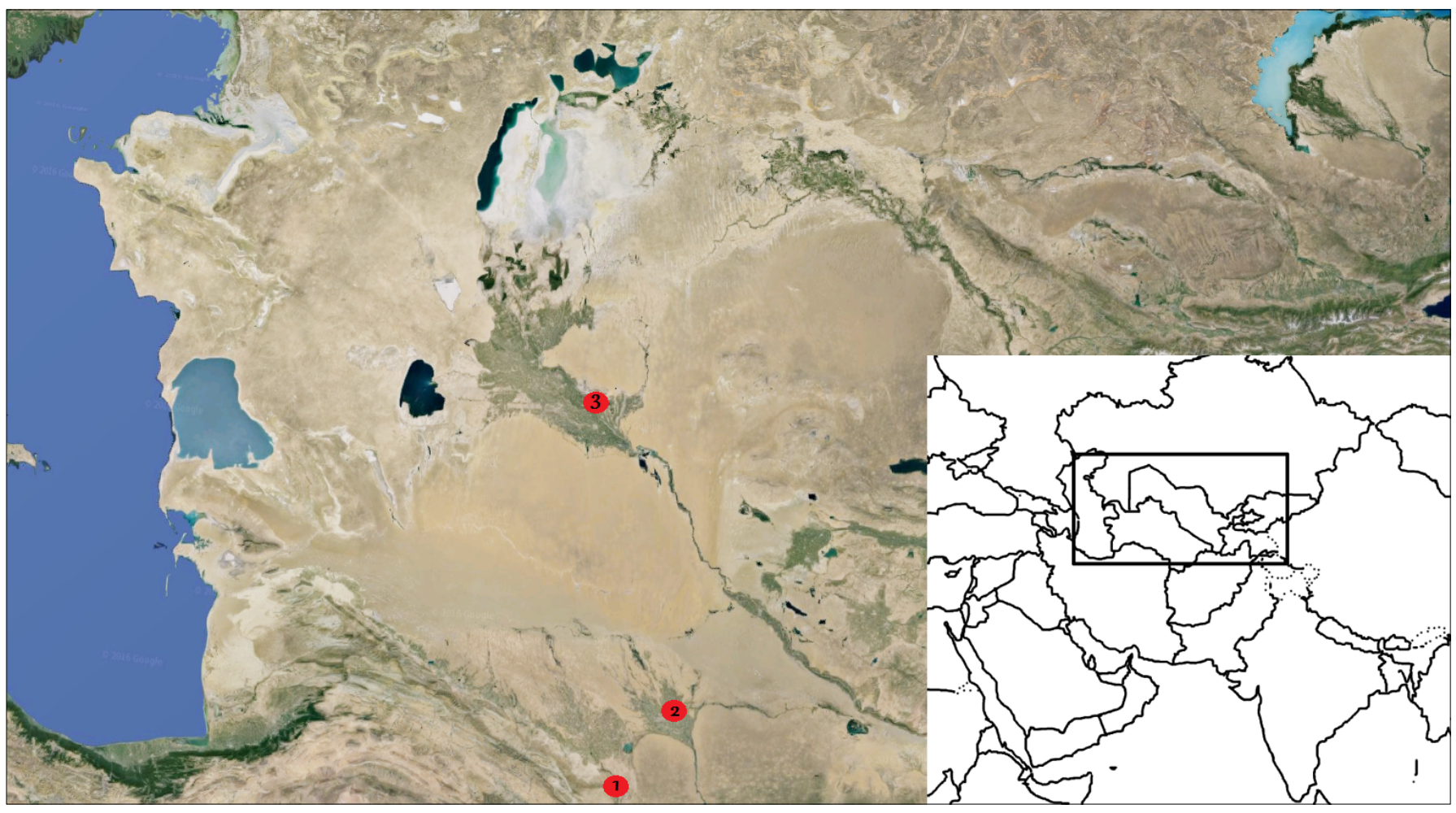

Figure 1 Map showing location of Gurukly Depe (1) and cotton seed finds in Central Asia from Merv (2) and Kara-Tepe (3).

from the surface is dated between the seventh to eighth centuries $\mathrm{AD}$.

\section{General Information about Spinning and Spindle Whorls}

Spindle whorls are normally symmetrical, circular objects with a perforation in the center (Figure 2). They were used to spin: i.e., to form continuous threads by pulling out and twisting fibers. Although there are many methods of spinning (e.g., handspinning without any equipment), the most popular method-since prehistoric times in the Old and New World-was spinning by twisting a stick (spindle) weighted with a whorl (Forbes 1956:152). The spindle is usually a straight, slightly tapered stick, which was normally made of wood, but sometimes of bone or metal. No spindles were found at Gurukly Depe, which suggests that they had been made of perishable materials. There are two places where the whorl may be attached to the spindle, at the top or bottom (rarely in the middle). These may relate to the way the spindle was used: for instance, if the spindle is turned on the thigh it is preferable to mount the whorl at the top, because hands roll the shaft of the spindle below. However, for drop spinning it is more convenient to install a whorl at the bottom (Carington Smith
1975:76). Drop spinning is the most popular type of spinning a spindle. Unspun fiber is often bound upon a distaff (smooth stick) held in the left hand, while the right hand draws out the staple (i.e., the fiber), which is twirled by the spindle rotating in mid-air. The whorl serves as a flywheel, keeping the spindle in circular motion. Drop spinning is a very frequent method of traditional flax and wool spinning. However, for spinning delicate yarn like cotton, the most appropriate technique is to rotate the spindle horizontally with fingers in mid-air or on a thigh, or to use a vertical spindle supported in a small bowl (Carpenter et al. 2012:386; Conlee 2000:346-347; Crowfood 1931:19, 41-42). Some yarn must be spun with more force, some with less, and at slower or faster speeds. These decisions depend on the length, thickness, and strength of the fiber, and on thickness of the yarn desired. For example, wool staple is much shorter than flax fiber. Therefore, to get a high number of twists in the resulting thread, woolen thread must be spun with a spindle that rotates much faster than a spindle with linen (flax) thread. However, cotton fiber is shorter and more delicate than both woolen and linen fibers, so the speed of spindle rotation must be faster. If a spinner has one type of fiber and wants to make thicker and thinner threads she/he must spin 


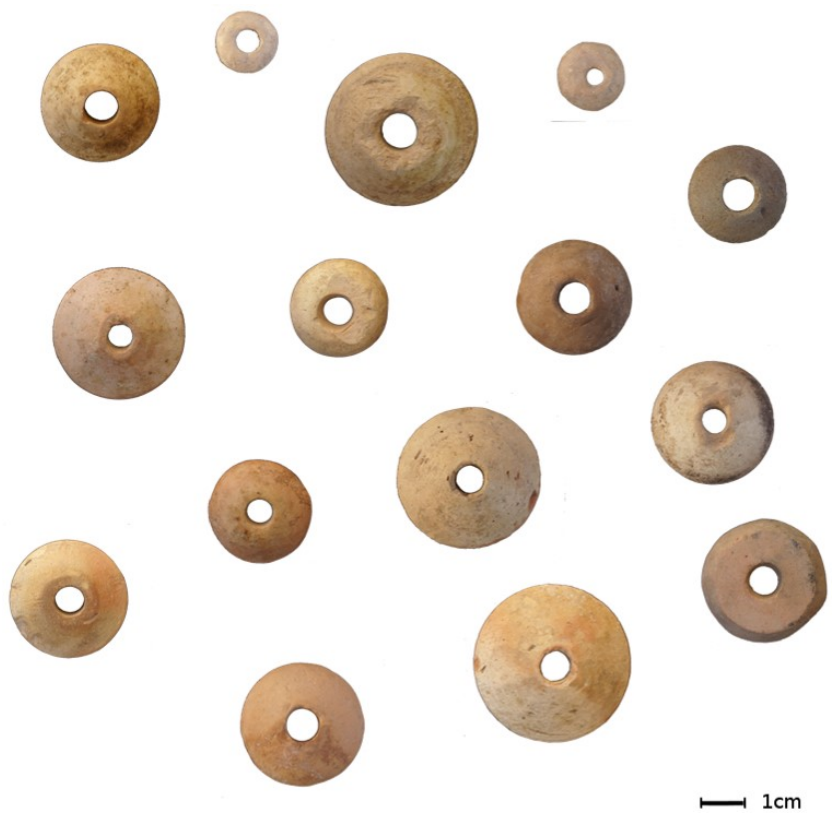

Figure 2 Some examples of spindle whorls. Photo by Barbara Kaim.

the former slower than the latter. A critical component is the whorl, as the weight and shape of spindle whorls have an influence on the kind of yarn spun.

\section{Moment of Inertia}

The ability of bodies to stay in a rotary motion around a given axis is dependent on bodies' mass and distance from the axis of rotation (radius). The product of those two parameters determines the value of the mass moment of inertia. In the case of a body consisting of set of points, like a whorl, this function is much more complicated (Chmielewski and Gardyński 2010:870-871; Verchecken 2009:257-270). Nonetheless, while investigating the mass moment of inertia of spindle whorls, the most important values are the mass, radius, and height of the whorl. The higher the moment of inertia, the slower and longer the rotation of the spindle. Therefore, cotton, as a fiber with a short staple, requires light whorls, while flax must be spun with a rather heavy whorl. Moreover, the weight of a spindle is dependent on the strength of the fiber. If the staple is thin and delicate, it is not possible to spin it with a heavy weighted spindle. The weight of the spindle should be adequate to tighten yarn just enough, but not too strongly.

\section{Archaeological Evidence Relating Whorl Size and Fiber Choice}

Textiles in Central Asia and Iran dating to the
Sasanian or post-Sasanian periods include only wool, cotton, silk, and sporadic linen fabrics (Belenitskij et al. 1963; Hansman and Stronach 1970:142-155; Kurbanov and Teplyakova 2014). ${ }^{3}$ There are no heavy whorls at Gurukly Depe, which are needed to spin heavy fibers such as hemp and flax, as described in the results below. This is hardly surprising, as the sandy soils of the Serakhs oasis are not conducive to the cultivation of flax. There is also no evidence for the use of other important bast fibers like sunn hemp, jute, kenaf, and nettle in the region (Good 2012:124). Here I consider the archaeological evidence for distinguishing whorls used to spin wool and cotton, and briefly consider silk in the concluding section of this article.

The steppe landscape of Turkmenistan is perfect for breeding sheep and goats. Therefore, wool fiber certainly was readily available at Gurukly Depe. According to Jill Carington Smith (1975:80-81) 10-40 $\mathrm{g}$ is the optimal weight for spindle whorls used to spin woolen thread. ${ }^{4}$ Christine Kimbrough, in her doctoral dissertation (2006), distinguished four groups of whorls used for making different woolen yarns: 8-19 $\mathrm{g}(2.5-5 \mathrm{~cm}$ in diameter) whorls could be used to spin delicate thread from short-staple sheep or goat hair; 20-35 g (3-4.9 cm in diameter) could be used to spin delicate thread from long-staple sheep fiber; 20-35 g (5-7 cm in diameter) could be used to produce medium thread from short-staple sheep fiber; and 36$60 \mathrm{~g}$ (5-7.5 cm in diameter) could be used to spin medium thread from long-staple sheep fiber (after Chmielewski 2009:125-126). Thanks to experiments conducted by technicians from the Danish National Research Foundation's Center for Textile Research at the University of Copenhagen, it has been shown that it is possible to spin woolen thread with a whorl weighing about $4 \mathrm{~g}$ (Mårtensson et al. 2006). This thread was extremely thin and delicate. It is doubtful that such light whorls were used to spin wool in the past. Karina Grömer (2005:109-110) spun woolen threads using original spindle whorls from Hallstatt. Whorls weighing 8-20 g were ideal for obtaining a thread $0.2-0.7 \mathrm{~mm}$ thick. Textiles made of $0.1-0.2$ mm woolen threads are known from few excavations (e.g., Maik 2012:73). These textiles were extremely thin and probable luxuries.

Therefore, although it is possible that very light whorls were used to spin wool, it is more likely that they were used to spin cotton. Mary Parsons (1972), in her analysis of spindle whorls from the Valley of 
Mexico, suggests that whorls weighting 1-13 $\mathrm{g}$ and measuring $1.5-3.8 \mathrm{~cm}$ in diameter were used to spin cotton. Very similar observations were made by Michael E. Smith and Kenneth G. Hirth (1988:350) in their study of spinning in Western Morelos (Mexico), where they proposed that spindle whorls for spinning cotton weighed approximately between 2-18 g. Light spindle whorls were discovered at some sites of the Peruvian coast where cotton was cultivated. For example, at the Pajonal Alto (Nasca) site, whorls of $0.6-10.8 \mathrm{~g}$, measuring $1.01-2.92 \mathrm{~cm}$ in diameter, were found. Some of them were discovered with a spindleshaft in them alongside cotton yarn (Conlee 2000: 340-347).

The results of cotton spinning research in Mesoamerica and South America can also be applied to studies of the history of weaving in Central Asia, despite the fact that American species of cotton (Gossypium birsutum and Gossypium barbadense) have a longer staple than Old Word cotton (Gossypium herbaceum and Gossypium arboreum). Unfortunately, to date there are very few archaeological or ethnographic studies that explore whorl weights used in Old Word cotton spinning. Archaeologists have found some spindle whorls in Kot Diji Phase (2800-2600 BC) contexts at the Harappa culture site of Mohenjo Daro. They can be divided into three groups: small, medium, and large (Kenoyer 2010:Table 9.2). Those from the first group weigh between $5.9 \mathrm{~g}$ and $13.9 \mathrm{~g}$ and have an average diameter of $2.4-3.0 \mathrm{~cm}$. It is probable that they were used to spin cotton, an indigenous fiber for the Indus Valley. Spindle whorls have been excavated at Meroitic sites, where cotton cultivation was introduced in the first to second centuries $\mathrm{AD}$, but most of this material has not yet been examined. Only whorls from Abu Geili have been studied carefully (Yvanez 2016). The site is dated to the late Meroitic period. No cotton seeds have been discovered at this site, despite carbonized sorghum seeds being attested (Yvanez 2016:173). However, cotton seeds and spindle whorls were both found at the Sasanian site of Erk Kala at Merv, Turkmenistan. Their weight is similar to Mesoamerican spindle whorls: $1.5-12$ g. ${ }^{5}$

\section{Analysis of Spindle Whorls from Gurukly Depe}

At Gurukly Depe, 102 possible spindle whorls were found. However, about 30\% of them are partially preserved whorls. They were mostly made of baked clay with mineral or organic components (92 specimens) but sometimes of stone (8) or pierced pottery sherds (2).

There are two main problems with investigating spinning and spindle whorls. First, not all artifacts that look like spindle whorls are spindle whorls. They might have been used as tools for other purposes or worn as beads. Secondly, as mentioned by Elizabeth W. Barber (1991:303), any symmetrical object can serve as a flywheel, even if it had a different original application. In this analysis, I consider as spindle whorls as all symmetrical, round objects with a standardized perforation in the center.

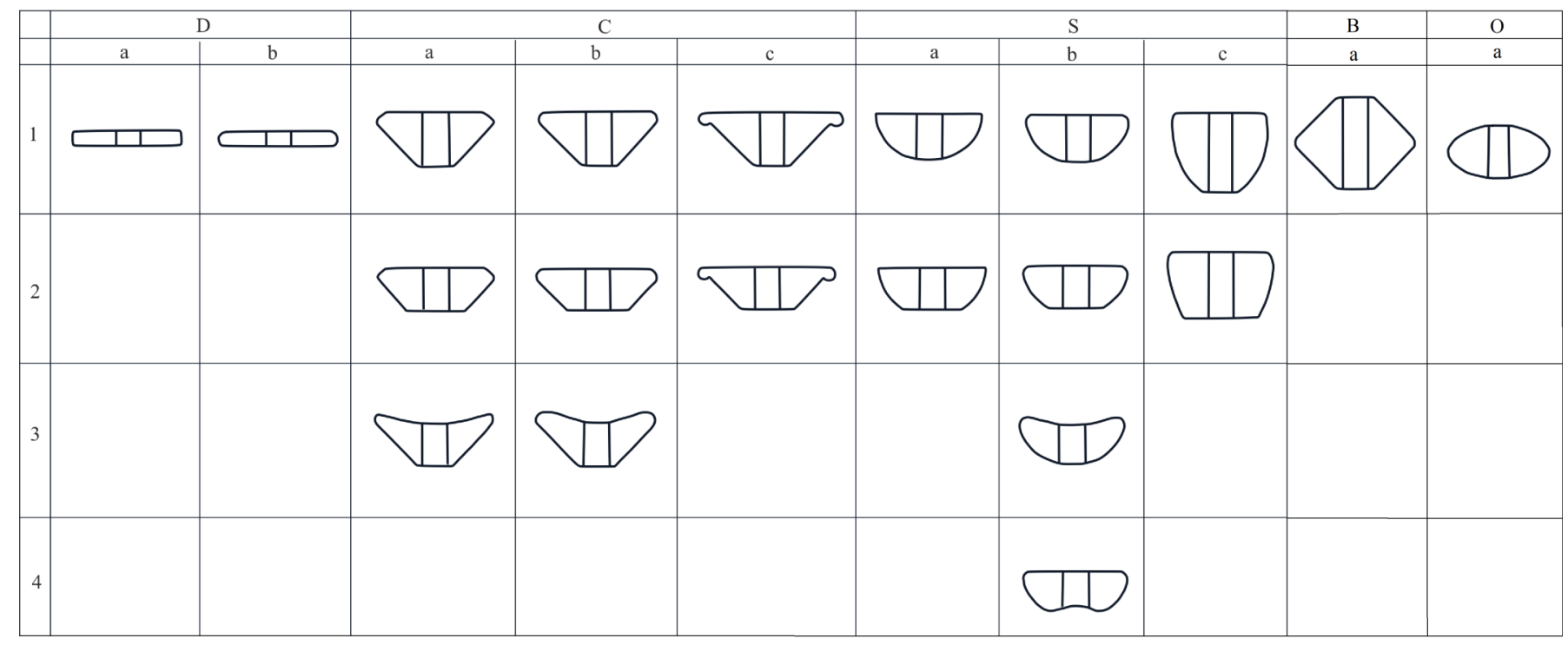

Figure 3 Typology of spindle whorls found at Gurukly Depe. 


\section{Typology}

Whorls can be divided into five groups: discoid (D), conical (C), spherical (S), biconical (B), and ovoid (O) (Figure 3). Almost half (47 \%) of whorls from Gurukly Depe are conical in shape. The ratio of spherical and discoid whorls is nearly equal: $22 \%(\mathrm{~S})$ to $24 \%$ (D). The last two types are very rare: biconical only comprise $4 \%$ of total whorls and ovoid $3 \%$. Shapes of whorls within the groups are very diverse. There are whorls with flat (a) or concave (b) bases, flattened tops (2) or concave bottoms (3), etc. Moreover, the whorls from Gurukly Depe are not standardized in relation to diameter and height (Figure 4). In fact, it is hard to find two identical objects. The distinctions identified in Figure 3 are not more than a rough attempt to make a typology of these spindle whorls.

\section{Ornamentation}

Some whorls were made more carefully, some more carelessly, but only ten whorls are ornamented. Eight of these are clay objects and two are of stone. The well elaborated conical shape whorl (GR11/6J/025) has incised radial wedge-shaped lines on the base. Similar wedges decorate the upper part of two whorls (GR10/P/6 and GR14/11F/46). A conical whorl (GR11/12I/031) has a circular line motif on the base. One whorl (GR10/P/4) is spherical, with a flattened top, and its bottom is ornamented with ray patterns. Four conical shaped whorls (GR14/11L/40, GR14/5S/14, GR14/11F/36, and GR14/10I/09/1) are decorated with molded circular lines. The most ornamented whorl $(\mathrm{GR} 14 / 11 \mathrm{~F} / 47)$ is decorated with geometrical motifs at the bottom and on the sides.

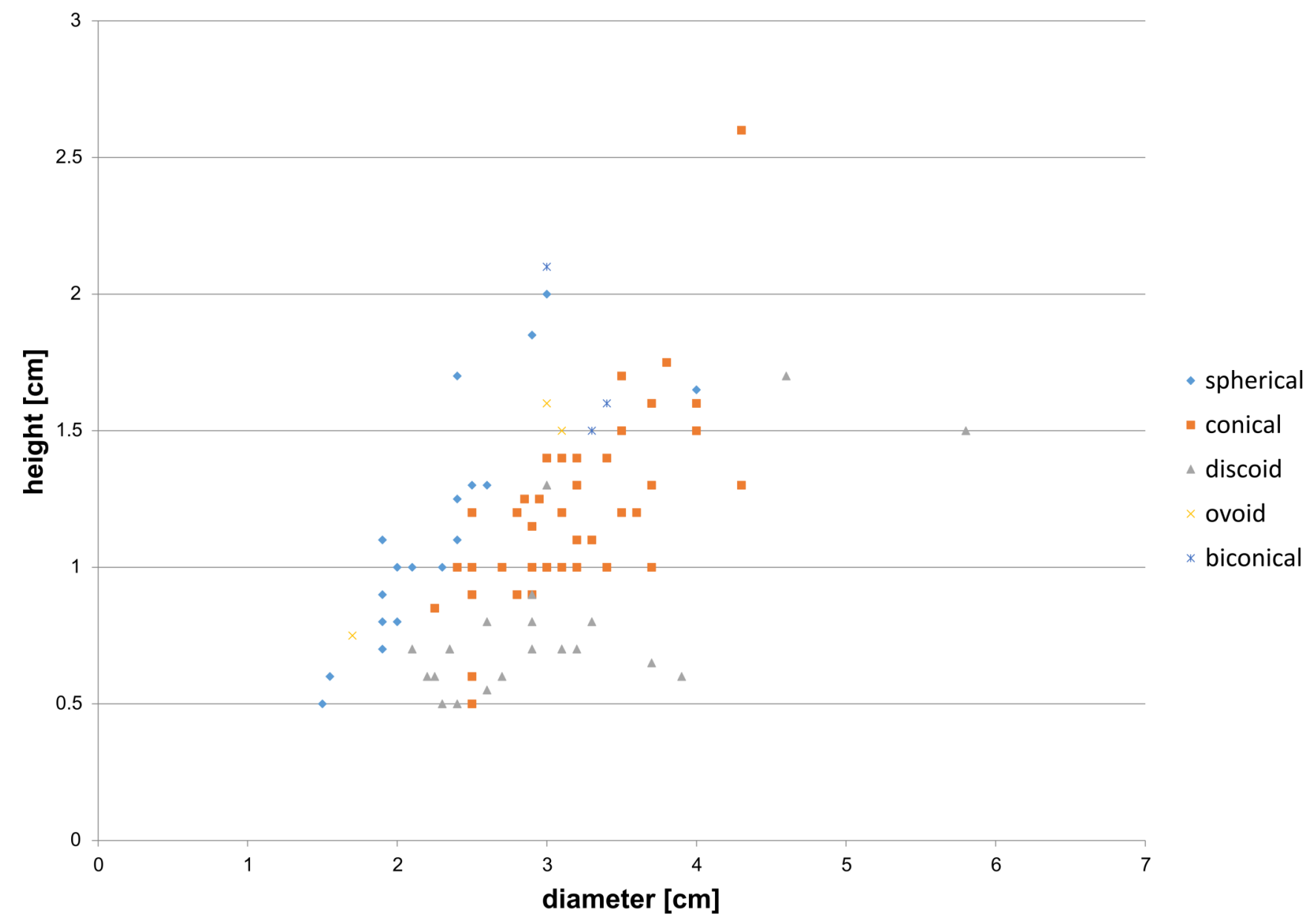

Figure 4 Diameters and heights of whorls found at Gurukly Depe. 


\section{Diameter and Height}

There is no distinct division between smaller and bigger spindle whorls found at Gurukly Depe (Figure 4). In all five groups, there are variations in whorls dimensions and weights. Generally, the diameter of spindle whorls ranges from 1.5 to $5.8 \mathrm{~cm}$, with discoid whorls $2.1-5.8 \mathrm{~cm}$ in diameter, spherical $1.5-4.0 \mathrm{~cm}$, conical $2.3-4.3 \mathrm{~cm}$, biconical $3.0-4.1 \mathrm{~cm}$, and ovoid $1.7-3.1 \mathrm{~cm}$. Depending on whorl shapes they are of various heights. Discoid whorls are 0.6 to $1.7 \mathrm{~cm}$ high, conical 0.5 to $2.6 \mathrm{~cm}$, spherical 0.5 to $2 \mathrm{~cm}$., biconical 1.5 to 2.1 , and ovoid 0.8 to 1.6. Among these variables, the most significant is the relation between diameter and height, the distinguishing factor between whorls used for different spinning tasks. Two whorls of the same weight but different dimensions have distinct moments of inertia, so the smaller the radius and greater the height, the smaller the moment of inertia. If so, it is not surprising that the smallest whorls found at Gurukly Depe are spherical. They would rotate very fast and they are perfect for preparing thin and delicate threads.

\section{Perforation Diameter}

Robert Liu (1978:97) noticed that the smallest spindle whorl perforations are 3-4 $\mathrm{mm}$ in diameter, but most common are perforations of $7-8 \mathrm{~mm}$, with the largest at $10 \mathrm{~mm}$. Spindle whorl perforations at Gurukly Depe extend from 5-8.5 $\mathrm{mm}$ in diameter, with the majority measuring 7-8 $\mathrm{mm}$. It is worth mentioning that the diameter of the perforation is not proportional to the size of a whorl. All spindle whorls have central perforations. In general, the perforation is rather cylindrical, however sometimes it tapers slightly towards the top. The difference between perforation diameter at the bottom and top of a whorl does not exceed one $\mathrm{mm}$.

It is worth noting that not only the weight and shape of the whorl is important to the spinning process, but also the parameters of the spindle shaft itself. There are no spindles from Gurukly Depe, but because of the standard sizes of whorl perforations, it is known that spindles had a standard thickness of 7-8 $\mathrm{mm}$ and probably a standard weight of $3-5 \mathrm{~g}$.

\section{Weight}

As mentioned above, the most important factor that influences whorl performance is weight. Whorls from Gurukly Depe are relatively light, with weights ranging from 1.9-25.5 g (Figure 5). ${ }^{6}$ Only three specimens are

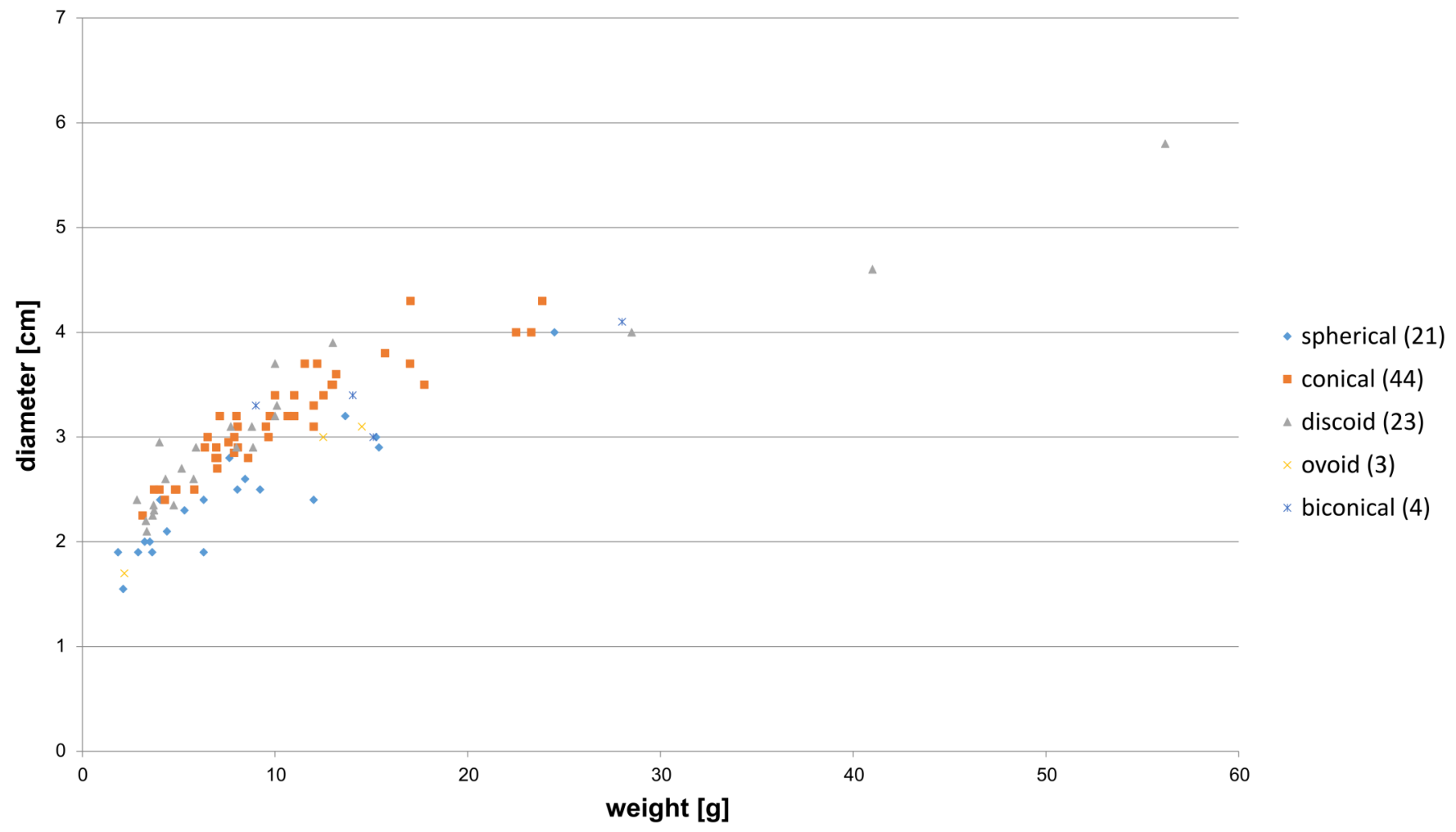

Figure 5 Reconstructed weight and diameter of whorls found at Gurukly Depe. 
40-60 $\mathrm{g}$ in weight (GR14/11F/47, GR14/P/09, and GR14/12G/01), but it is not certain if they served as spindle whorls. Among partially preserved objects this value is estimated. Therefore, to avoid any ambiguity, quantitative analyses were undertaken using only complete objects, and, separately (Figure 5), complete and partial whorls. Both graphs are very similar: most whorls weigh 3-9 g. Approximately $90 \%$ of all specimens are lighter than $18 \mathrm{~g}$.

\section{Cotton in Pre-Islamic Turkmenistan}

There is no direct evidence for cultivation of cotton during the Late Sassanian or Early Islamic periods at the Serakhs oasis. After the Arab conquest, in the ninth to tenth centuries $\mathrm{AD}$, the Merv oasis (ancient Margiana), located in eastern Turkmenistan, was one of the main centers of cotton production, of such quality that it was one of the Persian export goods (Serjeant 1972:87-92). However, archaeologists participating in the International Merv Project have found cotton seeds at the sites of Gyaur Kala and Erk Kala in Merv. Seeds are dated as early as the Middle (fourth to fifth centuries AD) and Late Sassanian (sixth to seven centuries AD) periods (Herrmann et al. 1993:56, 1994, 1995, 1996, 1997, 1998). Early cotton seeds were also identified at the site of KaraTepe in Khorezm, Uzbekistan. They were found in third to fifth century AD contexts (Brite and Marston 2013). When examining cotton seeds, it is not possible to determine cotton species, but Central Asian cotton was most likely Gossypium herbaceum var. persicum. G. herbaceum was domesticated in central Africa or more probably in the Arabian Peninsula, where the oldest cotton seeds date to the Achaemenid period (sixth century BC) (Bouchaud et al. 2011). ${ }^{7}$ Due to limited archaeobotanical data, it is hard to say when cotton cultivation began in Central Asia and the Near East. Based on archaeological data, an increase in cotton use took place during the Parthian period (c. 250 BC-225 AD) in the Near East. Cotton textiles were imported from Arabia, Egypt, and probably India, but it is probable that only in this period did cotton start to be introduced to the Near East and Central Asia as a crop.

\section{What was Being Spun at Gurukly Depe?}

The analysis of the weights and dimensions of spindle whorls found at Gurukly Depe suggests that the majority, if not all of them, could have served to spin cotton thread. If the weights and dimensions of whorls for spinning cotton are similar in Asia and Mesoamerica, then it seems reasonable to suggest that all whorls weighting 1-18 g and measuring 1.5-4.0 cm in diameter could have been used for cotton yarn production. Up to $90 \%$ of whorls found at Gurukly Depe in the Late Sasanian period fit in this range. Except for the three very heavy specimens mentioned above, the largest whorls are only slightly heavier and larger. It cannot be ruled out that they served in doubling or plying (twisting some threads together to make a thicker one) of cotton threads. Production of woolen yarn is probable, but not certain. Only $57 \%$ of whorls found at Gurukly Depe weight more than $8 \mathrm{~g}$, and are appropriate for spinning wool fiber as well. Furthermore, according to the division made by Kimbrough (2006), most of the whorls could have been used to produce only delicate threads made of short-staple sheep or goat wool. There are only a few examples of whorls of the size appropriate for spinning medium-thickness woolen yarn.

In the late Sasanian period, mulberry silk (produced by the silkworm, Bombyx mori) weaving was also possible in the area of present-day Turkmenistan. In the fifth century $\mathrm{AD}$, when, according to legend, a Chinese princess had smuggled mulberry seeds and silkworms to Khotan (currently in Xinjiang, western China), production of silk spread all over Central Asia (Forbes 1956:53), but the technology of silk production did not spread west of China until the sixth century AD (Good 1995:960). Generally, silk thread is reeled from the cocoon without the need for spinning. ${ }^{8}$ Although a light spindle could be used to double threads, most often silk thread was wound, doubled, and spooled by a rotating wooden reel or hand spindle wheel, which could have been known in China as early as the Shang period (1750-1100 BC) (Needham and Kuhn 1988:158-159). That traditional mechanism is still used by traditional Turkmen craftsmen (Ovezov 1959:169-187). Even if silk was produced at Gurukly Depe, silk thread was possibly made by using perishable wooden tools without ceramic or stone whorls.

\section{Conclusions}

Evidence from Gurukly Depe does not exclude wool or goat hair yarn production, but this analysis suggests that cotton fiber could have played a major role the textile economy of the Late Sasanian period at Gurukly Depe. Further investigation of Gurukly Depe, including flotation, zooarchaeological analysis, and further spindle whorls analysis, and at other sites in Turkmenistan will verify this hypothesis and provide new information about cotton cultivation in the pre-Islamic world of Central Asia. 


\section{Notes}

${ }^{1}$ The excavations were financed by Research Grant No. 2012/07/B/hS3/00908 from the National Science Center.

${ }^{2}$ Barbara Kaim, personal communications.

${ }^{3}$ Flax was known in Persia since Neolithic times. It was still cultivated in most parts of the Iranian Plateau during Medieval times (Wulff 1966:178).

4Jill Carington Smith (1975:80-81) carried out experiments and made ethnographic observations in Greece. Both findings were similar: whorls used to spin wool should weigh 10-40 g. M. Ryder conducted similar ethnographic observations in Afghanistan and noted that Afghan nomads used whorls weighing 8-33 $\mathrm{g}$ to spin different qualities of woolen yarn (after Chmielewski 2009:125).

${ }^{5} \mathrm{St}$ John Simpson, personal communications.

'In general, the weight of spindle whorls range from 1-150 g (Liu 1978:90).

${ }^{7}$ But is still unknown whether they were the species Gossypium herbaceum or G. arboreum.

${ }^{8}$ Wild silk has been spun, but there is a lack of historical and archaeological evidence that spinning was used in early times in Central Asia (Good 1995:959).

\section{Acknowledgements}

I would like to thank my mentor Professor Barbara Kaim and the team working at Gurukly Depe for their help in documentation.

\section{Declarations}

Permissions: None declared.

Sources of Funding: None declared.

Conflicts of Interest: None declared.

\section{References Cited}

Barber, E. J. W. 1991. Prehistoric Textiles: The Development of Cloth in the Neolithic and Bronze Ages with a Special Reference to the Aegean. Princeton University Press, Princeton, NJ.

Belenitskij, A. M., I. B. Bentovich, and V. A. Livshits. 1963. Kamchatnye tkani s Gory Mug Sovetskaja Etnografija 4:108-119.

Bouchaud, C., M. Tengberg, and P. Dal Prà. 2011. Cotton Cultivation and Textile Production in the Arabian Peninsula during Antiquity; The Evidence from Madâ’in Sâlih (Saudi Arabia) and Qal'at al-
Bahrain (Bahrain). Vegetation History and Archaeobotany 20:405-417. DOI:10.1007/s00334-011-0296-0.

Brite, E. B., and J. M. Marston. 2013. Environmental Change, Agricultural Innovation, and The Spread of Cotton Agriculture in the Old World. Journal of Anthropological Archaeology 32:39-53. DOI:10.1016/ j.jaa.2012.08.003.

Conlee, C. A. 2000. Late Prehispanic Occupation of Pajonal Alto, Nasca, Peru: Implications for Imperial Collapse and Societal Reformation. Doctoral Dissertation, University of California, Santa Barbara, CA. Available from ProQuest Dissertations and Theses database (UMI No. 3001454).

Carington Smith, J. 1975. Spinning, Weaving and Textile Manufacture in Prehistoric Greece, Volume I. Unpublished Doctoral Dissertation, University of Tasmania, Tasmania. Available at: http:// eprints.utas.edu.au/11442/. Accessed on March 16, 2016.

Carpenter, L. B., G. M. Feinman, and L. M. Nicholas. 2012. Spindle Whorls from El Palmillo: Economic Implications Latin American Antiquity 23:381-400. DOI:10.7183/1045-6635.23.4.381.

Chmielewski, T. J. 2009. Po nitce do ketebka... O przedzalnictwie $i$ tkactwie mtodszej epoki kamienia w Europie Środkowej. Semper, Warszawa, Poland.

Chmielewski, T. J., and L. Gardyński. 2010. New Frames of Archaeometrical Description of Spindle Whorls: A Case Study of the Late Eneolithic Spindle Whorls from the 1C Site in Gródek, District of Hrubieszow, Poland. Archaeometry 52:869-881. DOI:10.1111/j.1475-4754.2009.00507.x.

Crowfoot, G. M. 1931. Methods of Hand Spinning in Egypt and the Sudan. Bankfield Museum Notes 12. F. King and Sons, Halifax, United Kingdom.

Forbes, R. J. 1956. Studies in Ancient Technology, Volume IV. E. J. Brill, Leiden, Netherlands.

Good, I. 1995. On the Question of Silk in Pre-Han Eurasia. Antiquity 69:266:959-968. DOI:10.1017/ S0003598X00082491.

Good, I. 2012. Changes in Fiber Use and Spinning Technologies on the Iranian Plateau: A Comparative and Diachronic Study of Spindle Whorls ca 45002500 BCE. Paléorient 38:111-126. DOI:10.3406/ paleo.2012.5462.

Grömer, K. 2005. Efficiency and Technique Experiments with Original Spindle Whorls. In Hallstatt Textiles, Technical Analysis, Scientific Investiga- 
tion and Experiment on Iron Age Textiles, BAR Internatiolan Series 1351, edited by P. Bichler, Karina Grömer, Regina Hofmann-de Keijzer, Anton Kern, and Hans Reschreiter, pp. 107-116. Archaeopress, Oxford, United Kingdom.

Hansman, J., and D. Stronach. 1970. A Sasanian Repository at Shahr-i Qūmis. Journal of the Royal Asiatic Society of Great Britain and Ireland 2:142-155. DOI:10.1017/S0035869X0012831X.

Herrmann, G., V. M. Masson, and K. Kurbansakhatov. 1993. The International Merv Project, Preliminary Report of The Firs Season (1992). Iran 31:39_ 62. DOI:10.2307/4299886.

Herrmann, G., and K. Kurbansakhatov. 1994. The International Merv Project, Preliminary Report on the Second Season (1993). Iran 32:53-75.

DOI:10.2307/4299905.

Herrmann, G., and K. Kurbansakhatov. 1995. The International Merv Project, Preliminary Report on the Third Season (1994). Iran 33:31-60.

DOI:10.2307/4299922.

Herrmann, G., K. Kurbansakhatov, and St. J. Simpson. 1996. The International Merv Project, Preliminary Report on the Fourth Season (1995). Iran 34:1-22. DOI:10.2307/4299941.

Herrmann, G., K. Kurbansakhatov, and St. J. Simpson. 1997. The International Merv Project, Preliminary Report on the Fifth Season (1996). Iran 35:1-33. DOI:10.2307/4299956.

Herrmann, G., K. Kurbansakhatov, and St. J. Simpson. 1998. The International Merv Project, Preliminary Report on the Sixth Season (1997). Iran 36:53-75. DOI:10.2307/4299975.

Kaim, B. 2011. The First Season of Excavation at Gurukly Depe, Southern Turkmenistan, 2010. Światowit VIII (XLIX)/A (2009-2010):207-208.

Kenoyer, J. M. 2010. Measuring the Harappa World: Insights into the Indus Order and Cosmology. In The Archaeology of Measurement, Comprehending Heaven, Earth and Time in Ancient Societies, edited by I. Morley and C. Renfrew, pp. 106--121, Cambridge University Press, Cambridge, United Kingdom.

Kimbrough, C. K. 2006. Spindle Whorls, Ethnoarchaeology, and the Study of Textile Production in Third Millennium BCE Northern Mesopotamia: A Methodological Approach. Doctoral Dissertation, Department of Anthropology, New York University, New York. Available from ProQuest Disserta- tions and Theses database (UMI No. 3234150).

Kurbanov, S., and A. Teplyakova. 2014. Textiles Objects from the Citadel of Sanjar-Shah. Bulletin of Mibo Museum 15:167-177.

Needham, J., and D. Kuhn. 1988. Science and Civilization in China, Vol. V: Chemistry and Chemical Technology, Cambridge University Press, Cambridge, United Kingdom.

Maik, J. 2012. Wtókiennictwo Kultury Wielbarskiej. Institute of Archaeology and Ethnology of the Polish Academy of Sciences, Lódź, Poland.

Mårtensson, L., E. Andersson, M. Nosch, and A. Batzer. 2006. Technical Report Experimental Archaeology Part 2:2 Whorl or bead? Available at: http://ctr.hum.ku.dk/tools/Technical_report_22_experimental_arcaheology.PDF. Accessed on May 29, 2014.

Liu, R. K. 1978. Spindle Whorls. Part I. Some comments and speculations. The Bead Journal 3:87103.

Ovezov, D. M. 1959. Plemâ Murčadi, Trudy IuzhnoTurkmenistanskōi arkheologicheskoì kompleksnō ekspeditsii. Tom 9:135-282.

Parsons, M. 1972. Spindle Whorls from the Teotihuacán Valley, Mexico. In Miscellaneous Studies in Mexican Prehistory, Anthropological Papers No. 45, edited by M. W. Spence, J. R. Parsons and M. H. Parsons, pp. 45-79. University of Michigan, Museum of Anthropology, Ann Arbor, MI.

Różańska-Kardaś, M. 2013. Summary of Two Campaigns of Archaeological Fieldwork at the Gurukly Shaheri Caravanserai Site in the Serakhs Oasis, Southern Turkmenistan. Światowit 10:209_ 213.

Serjeant, R. B. 1972. Islamic Textiles: Material for a History Up to the Mongol Conquest. Librairie du Liban, Beirut, Lebanon.

Smith, M. E., and K. G. Hirth. 1988. The Development of Prehispanic Cotton Spinning Technology in Western Morelos, Mexico. Journal of Field Archaeology 15:349-358. DOI:10.1179/009346988791974466.

Verchecken, A. 2009. The Moment of Inertia: A Parameter for the Functional Classification of Worldwide Spindle-Whorls from all Periods. In North European Symposium for Archaeological Textiles X, edited by E. B. Andersson Strand, M. Gleba, U. Mannering, and C. Munkholt, pp. 257-270. Oxbow Books, Oxford, United Kingdom. 
Wulff, H. E. 1966. The Traditional Crafts of Persia: Their Development, Technology, and Influence on Eastern and Western Civilizations. MIT Press, Cambridge, Massachusetts, and London, United Kingdom.
Yvanez, E. 2016. Spinning in Meroitic Sudan: Textile

Production Implements from Abu Geili. A Journal of Nubian Studies 3:153-178. 